\title{
SUOMEN MAALAJIEN OMINAISPAINOSTA
}

\author{
Reijo Heinonen \\ Helsingin Yliopiston maanviljelyskemian laitos
}

Saapunut 3. 12. 1956

Kirjoittaja on joutunut maaperäfysikaalisten tutkimusten yhteydessä suorittamaan erilaisista maalajeista joukon ominaispainomäärityksiä, jotka koottuina tarjoavat mahdollisuuden yleiskuvan saamiseen Suomen maalajien ominaispainosta ja myös ominaispainon vaihteluiden syiden analysoimiseen. Kaikki määritykset on tehty alkoholipikamenetelmällä, joka oikein sovellettuna antaa pyknometrimenetelmän kanssa yhtäpitäviä tuloksia (1, p. 24)

Piirroksesta 1 ilmenee, että käytännöllisesti katsoen humusvapaiden pohjamaiden ominaispaino vaihteli rajoissa $2.66-2.82$ ollen keskimäärin 2.74. (Samat

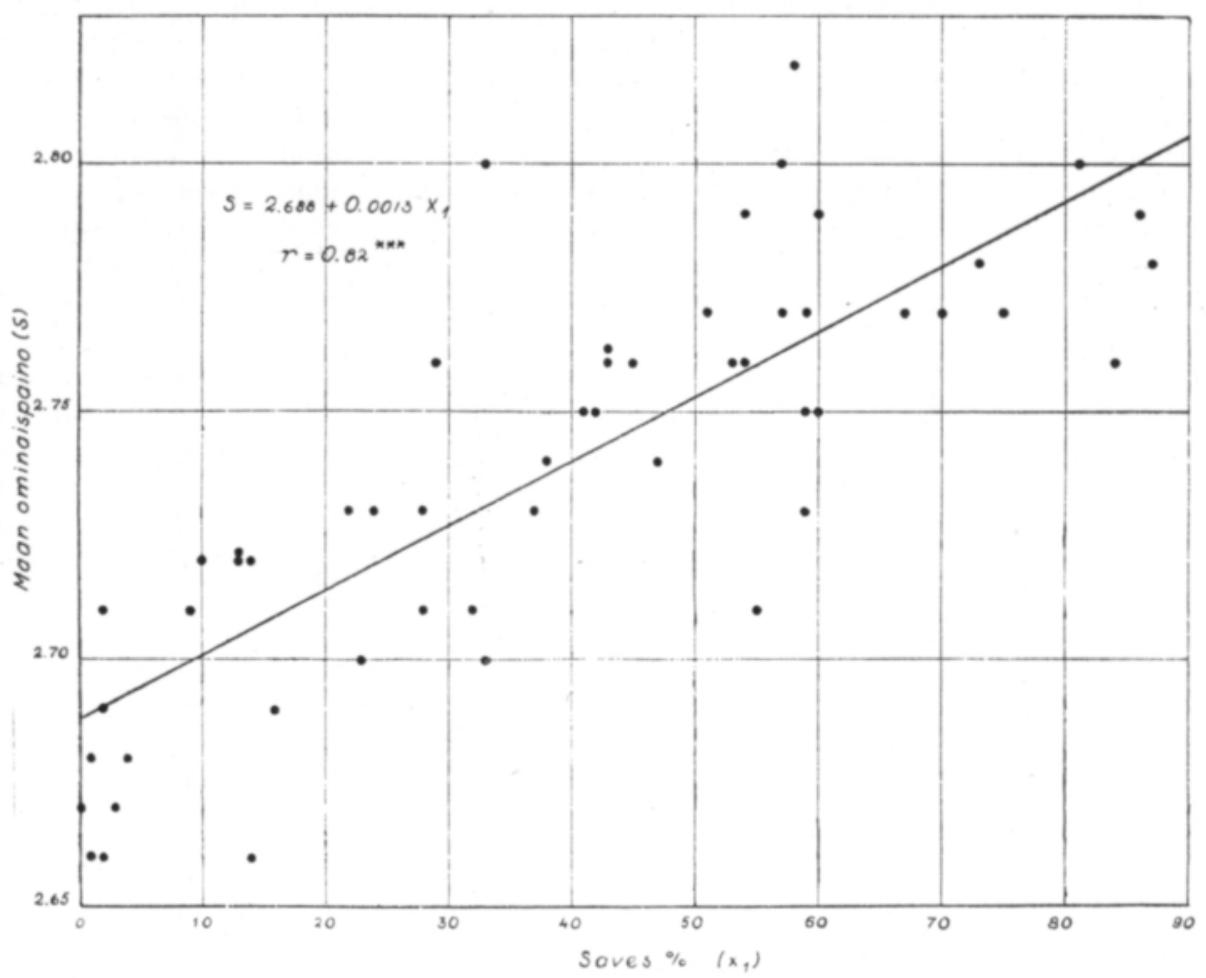

Piirros 1. Pohjanmaan $(40-80 \mathrm{~cm})$ ominaispainon riippuvuus savespitoisuudesta.

Fig. 1. The specific gravity $(S)$ of subsoils in relation to clay content $\left(x_{1}=\right.$ percent material $\left.<2 \mu\right)$. Sampling depth 40-80 cm, organic content $<1.25$ per cent. 


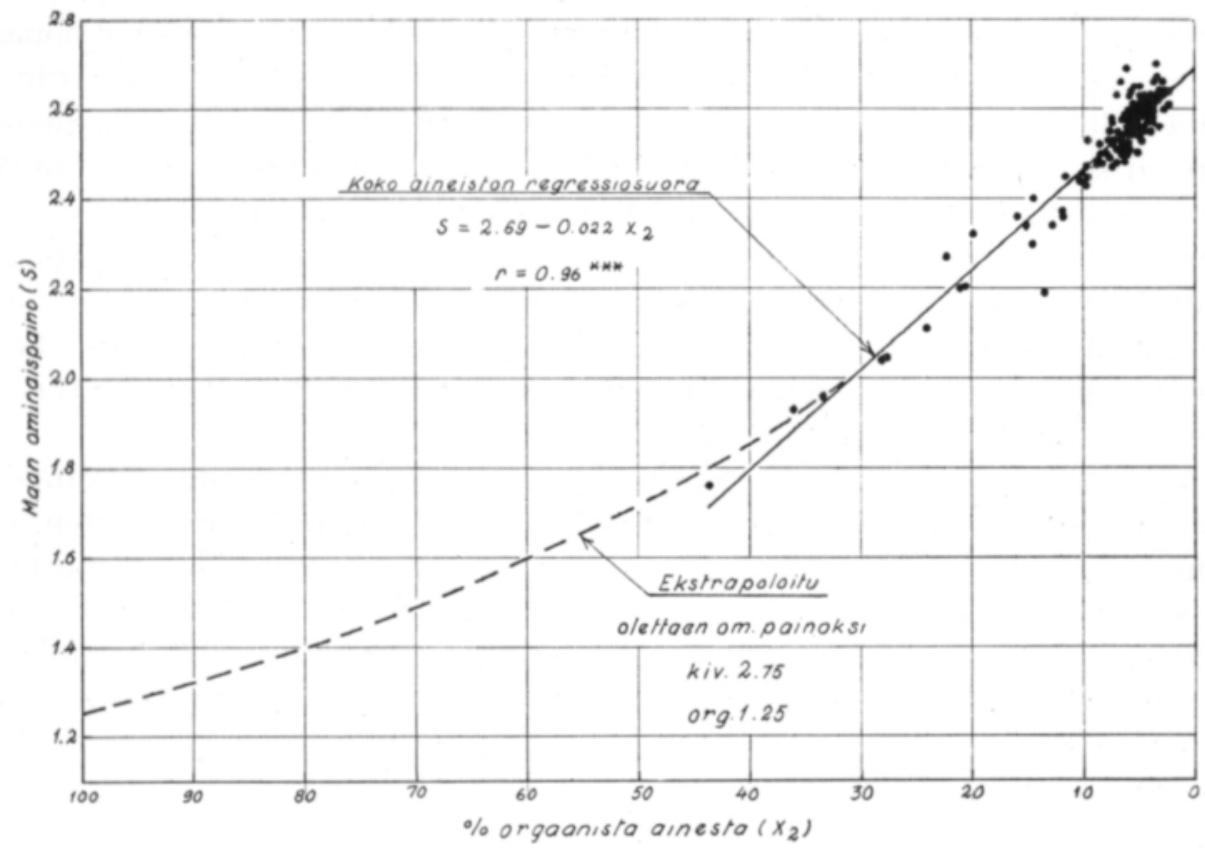

Piirros 2. Ruokamullan ominaispainon riippuvuus orgaanisen aineksen määrästä.

Fig. 2. The specific gravity $(S)$ of surface soils in relation to organic matter content $\left(x_{2}\right)$. Extrapolation (dotted line) based on the assumption that the specific gravity of mineral material is 2.75 and that of organic material 1.25.

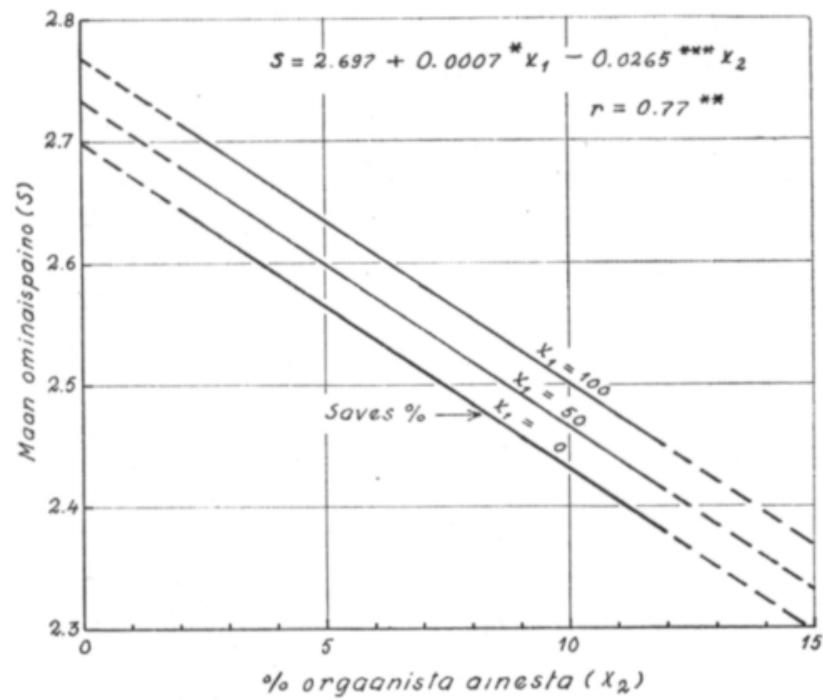

Piirros 3. Maan ominaispainon riippuvuus saves- ja humuspitoisuudesta $2-12 \%$ humusta sisältävästä aineistossa.

Figure 3. The specific gravity $(S)$ of surface soils containing $2-12$ per cent organic matter in relation to clay $\left(x_{1}\right)$ and organic matter percentage $\left(x_{2}\right)$. 
ääriarvot ja keskiarvo esiintyivät myös samanlaisessa kolme kertaa suuremmassa aineistossa, josta ei tehty mekaanisia analyysejä.) Tutkimusaineisto kerättiin eri puolilta etelä-Suomea, ja sen savespitoisuuden keskiarvo $40 \%$ lienee lähellä Suomen viljeltyjen kivennäismaiden pohjamaan keskimääräistä savespitoisuutta. Ominaispaino on selvässä korrelaatiossa savespitoisuuden kanssa, mikä onkin hyvin ymmärrettävissä, kun otetaan huomioon eri fraktioiden mineraalikoostumus. Karkeammat ainekset ovat kvartsivaltaisia, kun taas painavampi kiilleaines on helpommin jauhautuvana konsentroitunut savekseen (3). Korkein tässä aineistossa esiintynyt humuspitoisuus oli $1.25 \%$, joten humuspitoisuuden vaihtelu ei ole mainittavasti vaikuttanut tuloksiin.

Piirros 2 antaa yleiskuvan orgaanisen aineksen vaikutuksesta ruokamullan ominaispainoon. Tämäkin aineisto on kerätty eri puolilta etelä-Suomea siten, että se edustaa Suomen viljeltyjen kivennäismaiden koko tekstuuriasteikkoa, mutta eri paikoista kuin piirroksessa 1 esitetty pohjamaa-aineisto. Kun tämän koko aineiston jakautuma on vino, laskettiin vielä erikseen $2-12 \%$ humusta sisältävästä aineiston osasta (94 kpl,-suunnilleen normaali jakautuma) osittaisregressiolaskenralla ominaispainon (S) samanaikainen riippuvuus saves- ja humuspitoisuudesta $\left(\mathrm{x}_{1}\right.$ ja $\left.\mathrm{x}_{2}\right)$, jolloin saatiin piirroksessa 3 esitetty yhtälö.

Lähinnä pienemmän vaihteluvälin vuoksi korrelaatio jää supistetussa aineistossa jonkinverran heikommaksi kuin piirróksessa 2. Myös savespitoisuuden vaikutus esiintyy heikompana kuin pohjamaa-aineistossa (piirros 1), mutta muuten nämä kaksi erillistä aineistoa ovat hyvin yhtäpitäviä. Piirroksen 3 esittämän regression mukaan kivennäismaiden humuksen keskimääräinen ominaispaino olisi 1.3, josta arvot saattavat yksityistapauksissa poiketa $0.1-0.2$ (vrt. Segeberg 2).

KIRJALLISUUTTA

(1) Heinonen, R. 1954. Multakerroksen kosteussuhteista Suomen maalajeissa. Agrogeol. julk. 62: $1-82$.

(2) Segeberg, H. 1956. Zur Kenntnis der spezifischen Gewichte von Niedermoortorfen. Z. Pfl.ern. Düng. Bodenk. 71 (116): 133-141.

(3) SOVERI, U. 1956. The mineralogical composition of argillaceous sediments of Finland. Ann. acad. sci. fenn. Ser. A III. 48: 1-32.

SUMMARY :

ON THE SPECIFIC GRAVITY OF FINNISH SOILS

REIJO HEINONEN

Department of Agricultural Chemistry, University of Helsinki

The specific gravity of Finnish soils is directly correlated with the clay content. This is explained by the uniform mineralogical nature of Finnish soils. The heavy micaceous material is concentrated in the clay fraction. The effect of organic matter on the specific gravity is derived from the multiple regression analysis. 